\title{
When to transfuse: Red blood cell and platelet transfusion thresholds in clinical practice
}

\author{
C E Menard, ${ }^{1,2}$ MD; M Seftel, ${ }^{3}$ MB ChB, MPH; A Ponnampalam, ${ }^{1,2}$ MD; R Zarychanski, ${ }^{1,2,4}$ MD, MSc \\ ${ }^{1}$ Section of Hematology and Medical Oncology, Department of Internal Medicine, Max Rady College of Medicine, Rady Faculty of Health Sciences, \\ University of Manitoba, Winnipeg, Canada \\ ${ }^{2}$ Department of Medical Oncology and Hematology, CancerCare Manitoba, Winnipeg, Canada \\ ${ }^{3}$ Division of Hematology, Department of Medicine, University of British Columbia, Vancouver, Canada \\ ${ }^{4}$ Section of Critical Care, Department of Internal Medicine, Max Rady College of Medicine, Rady Faculty of Health Sciences, University of Manitoba, \\ Winnipeg, Canada
}

Corresponding author: M Seftel (matthew.seftel@bccancer.bc.ca)

Blood component transfusion is a frequently prescribed intervention in healthcare that depends on the availability of a limited and expensive resource. The transfusion of blood products may be life-saving, but it is not without risk. Society guidelines and clinical trials guide transfusion decisions regarding transfusion thresholds, as well as the appropriateness of prophylactic v. therapeutic transfusion strategies. This review provides a practical and evidence-informed approach to the transfusion of red blood cells and platelets in commonly encountered clinical settings.

S Afr Med J 2019;109(11):833-837. https://doi.org/10.7196/SAMJ.2019.v109i11.14317

The donor blood supply of any country is a limited and carefully regulated resource. With only $1 \%$ of South Africans being active blood donors, an evidence-informed approach to blood transfusion helps to ensure that blood products are given to individuals who may derive benefit from their administration. ${ }^{[1]}$ While blood transfusion is relatively safe, the potential for serious adverse events should be considered whenever a transfusion is ordered (Table 1). The annual Serious Hazards of Transfusion (SHOT) report details a risk of serious harm associated with transfusion as $\sim 1$ in 21000 and a risk of death as 1 in 117000 components issued in the UK. ${ }^{[2]}$ Blood transfusion should ideally be prescribed in the clinical setting where evidence supports efficacy, while balancing potential harm. Moreover, the indications for transfusion should be recognised promptly to reduce the sequelae of transfusion delays. Multiple trials, reviews and guidelines serve to inform appropriate transfusion thresholds in commonly encountered clinical contexts.

\section{Red blood cell transfusion}

\section{What is the ideal red blood cell transfusion threshold?}

The default red blood cell transfusion (haemoglobin $(\mathrm{Hb})$ ) threshold had been $10.0 \mathrm{~g} / \mathrm{dL}$ for $>40$ years, until a landmark clinical trial demonstrated that this liberal transfusion practice was largely unnecessary in the setting of critical care. ${ }^{[3]}$ Clinical trials have likewise demonstrated the safety of a restrictive transfusion strategy in a variety of clinical settings. Despite these trials, the 'optimal' red cell transfusion threshold is unknown and reflects our rudimentary understanding of short- and long-term physiological adaptations to anaemia and an individual's dynamic oxygen delivery needs. Despite these limitations, current transfusion thresholds identified through clinical trials provide a framework with which to approach patients.

\section{Non-bleeding hospitalised adult patients}

The Transfusion Requirements in Critical Care (TRICC) trial randomised non-bleeding euvolaemic critically ill patients to a 'restrictive' red cell transfusion strategy (threshold of $7.0 \mathrm{~g} / \mathrm{dL}$ ) v. a 'liberal' transfusion strategy (threshold of $10.0 \mathrm{~g} / \mathrm{dL}$ ). ${ }^{[3]}$ This landmark trial published in 1999 showed for the first time that a restrictive transfusion strategy was safe and may even be beneficial in specific patient populations. A restrictive transfusion threshold resulted in a $54 \%$ decrease in the number of red cell transfusions administered. Furthermore, $33 \%$ of patients in the restrictive arm were not transfused compared with $0 \%$ of the liberal arm. Subsequently, studies have been conducted in various patient populations, including orthopaedic and cardiac surgery, sepsis and haematopoietic cell transplantation (HCT). A Cochrane systematic review and meta-analysis recently evaluated clinical outcomes associated with restrictive $(7.0-9.0 \mathrm{~g} / \mathrm{dL})$

Table 1. Selected risks associated with blood product transfusion $^{[17]}$

\begin{tabular}{|c|c|}
\hline Risk $^{*}$ & Blood product transfusion \\
\hline 1 in 13 & $\begin{array}{l}\text { Red cell sensitisation (increased risk } \\
\text { for haemolytic transfusion reaction and } \\
\text { haemolytic disease of the newborn) }\end{array}$ \\
\hline 1 in 20 & $\begin{array}{l}\text { Febrile non-haemolytic transfusion } \\
\text { reaction per pool of platelets }\end{array}$ \\
\hline 1 in 100 & $\begin{array}{l}\text { Transfusion-associated circulatory } \\
\text { overload }\end{array}$ \\
\hline 1 in 100 & Urticaria \\
\hline 1 in 300 & $\begin{array}{l}\text { Febrile non-haemolytic transfusion } \\
\text { reaction per red blood cell unit } \\
\text { transfused }\end{array}$ \\
\hline 1 in 7000 & Delayed haemolytic transfusion reaction \\
\hline 1 in 10000 & Transfusion-related acute lung injury \\
\hline 1 in 40000 & Serious allergic reaction \\
\hline 1 in 13000000 & Hepatitis $C$ virus infection \\
\hline 1 in 7500000 & Hepatitis B virus infection \\
\hline 1 in 21000000 & HIV infection \\
\hline
\end{tabular}


v. liberal $(10.0 \mathrm{~g} / \mathrm{dL})$ transfusion thresholds in 12587 hospitalised patients enrolled in 31 randomised trials. ${ }^{[4]}$ Restrictive transfusion strategies reduced the relative risk of receiving a blood transfusion by $43 \%$ and did not significantly impact relevant clinical outcomes. Uncertainty remains surrounding the optimal transfusion threshold in acute coronary syndromes (ACS) and traumatic brain injury (TBI); both are being evaluated in ongoing clinical trials (Myocardial Ischemia and Transfusion (MINT) trial for ACS (NCT02981407), and the HEMOglobin Transfusion Threshold in Traumatic brain Injury OptimizatioN (HEMOTION) trial for TBI (NCT03260478)).

Based on the data described above, a transfusion threshold of $7.0 \mathrm{~g} / \mathrm{dL}$ is recommended for haemodynamically stable non-bleeding hospitalised patients, including those who are critically ill (Table 2). Most professional guidelines recommend that blood transfusions be used in symptomatic anaemia (chest pain, orthostatic hypotension, tachycardia unresponsive to fluid resuscitation or congestive heart failure) provided the $\mathrm{Hb}$ is $<10.0 \mathrm{~g} / \mathrm{dL} .{ }^{[4]}$ Despite a lack of randomised clinical trial data to support the adoption of a higher threshold, the American Association of Blood Banks (AABB) recommends a transfusion threshold of $8.0 \mathrm{~g} / \mathrm{dL}$ in patients undergoing orthopaedic or cardiac surgery, and for those with pre-existing cardiovascular disease. ${ }^{[5]}$ The recently published Transfusion Requirements in Cardiac Surgery (TRICS) III trial, demonstrating non-inferiority of a restrictive transfusion threshold of $7.5 \mathrm{~g} / \mathrm{dL}$ in cardiac surgery, corroborates that a lower threshold is well tolerated in cardiac surgery patients. ${ }^{[6]}$ In the setting of ACS, society guidelines support variable transfusion thresholds of $>8.0-10.0 \mathrm{~g} / \mathrm{dL}$, while we await randomised data to better inform transfusion decisions in this patient population (Table 2). ${ }^{[5,7]}$

\section{Bleeding hospitalised adult patients}

In a single, large randomised controlled trial (RCT) of patients with gastrointestinal (GI) bleeding, a restrictive transfusion threshold of $7.0 \mathrm{~g} / \mathrm{dL}$ (v. $9.0 \mathrm{~g} / \mathrm{dL}$ ) was associated with fewer red cell units transfused, less re-bleeding and increased survival at 30 days. $^{[4]}$ As such, haemodynamically stable patients with GI bleeding should be managed with a transfusion threshold of $7.0 \mathrm{~g} / \mathrm{dL}$ (Table 2). In the context of massive transfusion protocols (MTPs) designed to provide optimal red blood cell (RBC):plasma:platelet ratios, the ideal transfusion threshold in massive transfusion is unknown. In the absence of randomised trials, maintaining a nadir $\mathrm{Hb}>8.0 \mathrm{~g} / \mathrm{dL}$ is pragmatic; however, transfusion decisions should consider the clinical context and be modified by laboratory testing.

\section{Ambulatory patients with chronic transfusion requirements}

There are limited randomised clinical trial data to guide outpatient transfusion thresholds. Two ongoing prospective pilot studies (NCT 02099669; ISRCTN 26088319) are evaluating optimal transfusion thresholds in myelodysplastic syndrome (MDS). These studies will evaluate the impact of liberal $(\mathrm{Hb}$ target $>11.0 \mathrm{~g} / \mathrm{dL}) \mathrm{v}$. restrictive $(\mathrm{Hb}$ target $>8.5 \mathrm{~g} / \mathrm{dL}$ ) transfusion strategies on quality of life. Given the established safety of restrictive transfusion strategies in critically ill and hospitalised patients, and with the added concerns for increased risks of allo-immunisation and iron overload due to chronic transfusion, consensus recommendations suggest a restrictive transfusion threshold (typically $8.0-9.0 \mathrm{~g} / \mathrm{dL}$ ) in most ambulatory patients with acquired marrow failure syndromes (Table 2).

\section{Platelet transfusion}

Should platelets be transfused prophylactically, and at what platelet count threshold?

Similar to RBC transfusion decisions, the appropriateness of platelet transfusion must be considered in each specific clinical setting. Prophylactic transfusion strategies (i.e. transfusion at a pre-specified platelet count threshold to reduce the risk of bleeding) are important in the supportive care of many patients, but evolving evidence suggests that therapeutic transfusion strategies (i.e. at the first sign of bleeding) may be appropriate in specific clinical settings.

\section{Therapy-induced reversible myelosuppression}

Prophylactic platelet transfusion strategies at platelet count thresholds of $<10 \times 10^{9} / \mathrm{L}$ in patients with haematological malignancies who have therapy-related thrombocytopenia have been shown to primarily reduce the risk of World Health Organization (WHO) grade 2 bleeding (Tables 3 and 4). ${ }^{[8]}$ These results have been extrapolated to formulate recommendations in other settings of therapy-related hypoproliferative marrow states. ${ }^{[9-11]}$ It is also recommended that prophylactic platelet transfusion (threshold of $<10 \times 10^{9} / \mathrm{L}$ ) be used for patients undergoing allogeneic $\mathrm{HCT}^{[8]}$ In the setting of autologous HCT, subgroup analysis of two RCTs demonstrates that therapeutic (compared with prophylactic) platelet transfusion strategies reduce platelet transfusions without impacting rates of

Table 2. Recommended red blood cell transfusion thresholds ${ }^{[5,7]}$

\begin{tabular}{|c|c|c|c|}
\hline Clinical setting & $\begin{array}{l}\text { Transfusion } \\
\text { threshold, g/dL }\end{array}$ & $\begin{array}{l}\text { Strength of } \\
\text { recommendation }\end{array}$ & Quality of evidence \\
\hline \multicolumn{4}{|l|}{ Non-bleeding hospitalised patients } \\
\hline Haemodynamically stable (including critically ill ${ }^{\star}$ ) & 7.0 & Strong & Moderate \\
\hline Haematopoietic cell transplant & 7.0 & Strong & Moderate \\
\hline Cardiac surgery (postoperatively) & 7.5 & Strong & Moderate \\
\hline Non-cardiac surgery $^{\dagger}$ & 8.0 & Weak & Low \\
\hline Pre-existing cardiovascular disease & 8.0 & Weak & Low \\
\hline Acute coronary syndrome & $8.0-10.0$ & Weak & Very low \\
\hline Traumatic brain injury & $8.0-10.0$ & Weak & Very low \\
\hline \multicolumn{4}{|l|}{ Bleeding hospitalised patients } \\
\hline Haemodynamically stable gastrointestinal bleeding & 7.0 & Strong & Moderate \\
\hline \multicolumn{4}{|l|}{ Ambulatory patients } \\
\hline Acquired marrow failure & $8.0-9.0$ & Weak & Very low \\
\hline Chemotherapy-induced marrow suppression & $8.0-9.0$ & Weak & Very low \\
\hline
\end{tabular}


major bleeding (WHO grade 3 or 4 bleeding; Table 3). Given these data, several society guidelines currently suggest a therapeutic platelet transfusion strategy for patients undergoing autologous HCT (Table 4). ${ }^{[9,11]}$ This approach requires inpatient-based monitoring with platelet transfusion at the first sign of clinically significant bleeding (WHO grade 2 or higher bleeding). As the aforementioned clinical trials have demonstrated that many of these patients continue to experience bleeding complications despite platelet transfusion,

Table 3. Summary of the modified WHO bleeding scale ${ }^{[16]}$

\begin{tabular}{|c|c|}
\hline WHO bleeding grade & Examples \\
\hline 1 & $\begin{array}{l}\text { - Oropharyngeal bleeding } \leq 30 \mathrm{~min} \text { in } 24 \mathrm{~h} \\
\text { - Epistaxis } \leq 30 \mathrm{~min} \text { in previous } 24 \mathrm{~h} \\
\text { - Petechiae of oral mucosa or skin } \\
\text { - Purpura } \leq 2.5 \mathrm{~cm} \text { in diameter } \\
\text { - Spontaneous haematoma in soft tissue or muscle } \\
\text { - Positive stool occult blood test } \\
\text { - Microscopic haematuria or haemoglobinuria } \\
\text { - Abnormal vaginal bleeding (spotting) }\end{array}$ \\
\hline 2 & $\begin{array}{l}\text { - Epistaxis }>30 \mathrm{~min} \text { in } 24 \mathrm{~h} \\
\text { - Purpura }>2.5 \mathrm{~cm} \text { in diameter } \\
\text { - Joint bleeding } \\
\text { - Melanotic stool } \\
\text { - Haematemesis } \\
\text { - Gross (visible) haematuria } \\
\text { - Abnormal vaginal bleeding (more than spotting) } \\
\text { - Haemoptysis } \\
\text { - Visible blood in body cavity fluid } \\
\text { - Retinal bleeding without visual impairment } \\
\text { - Bleeding at invasive sites }\end{array}$ \\
\hline 3 & $\begin{array}{l}\text { - Bleeding requiring red blood cell transfusion over routine transfusion needs } \\
\text { - Bleeding associated with moderate haemodynamic instability }\end{array}$ \\
\hline 4 & $\begin{array}{l}\text { - Bleeding associated with severe haemodynamic instability } \\
\text { - Fatal bleeding } \\
\text { - CNS bleeding on imaging study with or without dysfunction }\end{array}$ \\
\hline
\end{tabular}

Table 4. Prophylactic platelet transfusion threshold $s^{*[9-11,15]}$

\begin{tabular}{|c|c|c|c|}
\hline Clinical setting & Transfusion threshold & $\begin{array}{l}\text { Strength of } \\
\text { recommendation }\end{array}$ & $\begin{array}{l}\text { Quality of } \\
\text { evidence }\end{array}$ \\
\hline Treatment-related marrow suppression $^{\dagger}$ & $<10 \times 10^{9} / \mathrm{L}$ & Strong & Moderate \\
\hline Autologous haematopoietic cell transplantation & Not recommended & Weak & Moderate \\
\hline Chronic irreversible marrow failure & Not routinely required & Weak & Low \\
\hline Critical illness & $<10 \times 10^{9} / \mathrm{L}$ & Weak & Low \\
\hline Immune thrombocytopenia & Not recommended & Strong & Low \\
\hline Thrombotic thrombocytopenic purpura ${ }^{\S}$ & Contraindicated & Strong & Low \\
\hline Prior to bone marrow biopsy & Not routinely required & Weak & Low \\
\hline Prior to paracentesis & Not routinely required & Weak & Low \\
\hline Prior to bronchoscopy with lavage & $<20 \times 10^{9} / \mathrm{L}$ & Weak & Low \\
\hline Prior to chest tube insertion or thoracentesis & $<50 \times 10^{9} / \mathrm{L}$ & Weak & Low \\
\hline Prior to elective central venous catheters & $<20 \times 10^{9} / \mathrm{L}$ & Weak & Low \\
\hline Prior to elective diagnostic lumbar puncture & $<50 \times 10^{9} / \mathrm{L}$ & Weak & Very low \\
\hline Prior to urgent diagnostic lumbar puncture & $<20 \times 10^{9} / \mathrm{L}$ & Weak & Very low \\
\hline Prior to major elective surgery (excluding neurosurgery) & $<50 \times 10^{9} / \mathrm{L}$ & Weak & Very low \\
\hline Prior to neurosurgery & $<100 \times 10^{9} / \mathrm{L}$ & Weak & Low \\
\hline Traumatic brain injury/intracranial haemorrhage & $<100 \times 10^{9} / \mathrm{L}$ & Weak & Low \\
\hline Prior to insertion of an intraventricular drain & $<100 \times 10^{9} / \mathrm{L}$ & Weak & Low \\
\hline \multicolumn{4}{|c|}{$\begin{array}{l}{ }^{*} \text { May be modified by individual patient factors that may increase bleeding risk, including comorbidities, use of antiplatelet/anticoagulants and clinical status. } \\
\text { 'Reversible bone marrow suppression (i.e. chemotherapy induced), including allogeneic haematopoietic cell transplantation, but not including inpatient autologous haematopoietic cell } \\
\text { transplantation. } \\
\text { tConsider prophylaxis for patients with recurrent bleeding (World Health Organization grade } 2 \text { or higher }{ }^{[19]} \text { ) and for those who are potential candidates for allogeneic haematopoietic cell } \\
\text { transplantation. } \\
\text { splatelet transfusions should only be used for life-threatening bleeding. } \\
\text { 'Inserted with bedside ultrasound and by experienced personnel. Avoid non-compressible vessels if platelets are }<50 \times 10^{9} / \mathrm{L} \text {. Choosing a compressible site is preferable to a prophylactic platelet } \\
\text { transfusion. }\end{array}$} \\
\hline
\end{tabular}


two ongoing clinical trials, TRial to EvaluAte Tranexamic Acid Therapy in Thrombocytopenia (TREATT; NCT03136445) and Platelet Transfusion Requirements in Hematopoietic Transplantation (PATH; NCT02650791), evaluate the prophylactic use of tranexamic acid to prevent bleeding in patients with severe thrombocytopenia and haematological malignancies.

\section{Critically ill patients}

Despite a lack of high-quality prospective data, prophylactic platelet transfusions at platelet thresholds of $<10 \times 10^{9} / \mathrm{L}$ are recommended in the setting of critical illness with reversible marrow failure (Table 4). ${ }^{\left[{ }^{[9}\right.}$

\section{Irreversible bone marrow failure (congenital or acquired)}

A recent systematic review identified one small RCT $(N=9)$ of therapeutic platelet transfusion strategies in MDS that was terminated early due to poor recruitment. ${ }^{[12]}$ The paucity of data to inform decision-making, highlights the need for trials in this clinical context. A single retrospective study in severe aplastic anaemia evaluated outcomes associated with a prophylactic transfusion strategy (platelet threshold of $\leq 5 \times 10^{9} / \mathrm{L}$ ). All deaths from haemorrhage were associated with preceding platelet alloimmunisation or palliation, and only three episodes of non-fatal major bleeding occurred. ${ }^{[13]}$ Due to the risks of platelet alloimmunisation, and the economic burden associated with a chronic transfusion programme, several international guidelines recommend a therapeutic transfusion strategy unless there is evidence of recurrent bleeding (WHO grade 2 or higher (Tables 3 and 4)). ${ }^{[9,11]}$ A caveat to this would be for potential candidates of allogeneic HCT, where a prophylactic transfusion strategy (platelet threshold of $<10 \times 10^{9} / \mathrm{L}$ ) is reasonable.

\section{Immune thrombocytopenia and thrombotic thrombo- cytopenic purpura}

Prophylactic transfusion strategies are not recommended in the routine management of immune thrombocytopenia (ITP) owing to the ineffectiveness of platelet transfusion in this setting, as well as the potential of exacerbating the underlying prothrombotic disease state. In ITP, platelet transfusion should only be given therapeutically in serious bleeding situations or prior to urgent surgical/procedural interventions, perhaps also with the co-administration of intravenous immunoglobulin to reduce platelet consumption. In the absence of lifethreatening bleeding, prophylactic platelet transfusions are likewise contraindicated in the setting of thrombotic thrombocytopenic purpura (TTP), where studies have indicated an increase in mortality associated with platelet transfusions. ${ }^{[9]}$

\section{Before procedures or surgery}

The need for prophylactic transfusion strategies prior to surgery or procedures has not been sufficiently evaluated in RCTs. ${ }^{[14]}$ Existing recommendations are derived from observational studies that describe clinical outcomes following platelet transfusion for specific platelet thresholds (Table 3). ${ }^{[15]}$

\section{What is the appropriate dose of prophylactic platelet transfusion?}

A large clinical trial $(N=1272)$, the Prophylactic Platelet Dose (PLADO) trial, demonstrated that in patients with hypoproliferative marrow disorders, low-dose platelet transfusions prescribed prophylactically at platelet concentrations of $<10 \times 10^{9} / \mathrm{L}$ were as effective as higher doses of platelets in preventing WHO grade 2 or higher bleeding complications. ${ }^{[16]}$ Accordingly, in non-bleeding patients, if a prophylactic platelet transfusion strategy is adopted, guidelines recommend transfusion with one adult dose of platelets. ${ }^{[9,10]}$ In the absence of consumption or destruction, each platelet dose should increase an adult patient's platelet count by $15-25 \times 10^{9} / \mathrm{L}$ when measured at 1 hour. If a platelet increment of $<10 \times 10^{9} / \mathrm{L}$ is achieved post-transfusion on more than one occasion, platelet refractoriness and the need for consultation with transfusion medicine experts are suggested. ${ }^{[17]}$

\section{Are transfusion 'thresholds' the best determinant of the need for transfusion?}

While the adoption of specific transfusion thresholds can prevent overutilisation of blood products, it is equally important to acknowledge the limitations of 'threshold' decisions in clinical practice. Clinical scenarios are varied and require a nuanced interpretation of the risks and benefits of transfusion. This notion is highlighted in the setting of anaemia of chronic disease. This condition is often viewed as deleterious due to the assumed reduction in oxygen delivery to tissues, as well as the association of anaemia with poor prognosis in many clinical disorders, but these notions are debatable. Firstly, the ability of the body to compensate for the often mild to moderate anaemia $(\mathrm{Hb}>8.0 \mathrm{~g} / \mathrm{dL})$ observed in chronic disease through both increased oxygen unloading and increased oxygen tissue extraction is typically sufficient to maintain adequate oxygen delivery ${ }^{[18]}$ Secondly, while anaemia is associated with increased mortality in many diseases, it is not proof of causation. Several studies have shown that when disease severity and inflammation are accounted for, anaemia of chronic disease is no longer prognostic for mortality. Moreover, the development of anaemia in response to systemic disease is evolutionally conserved in animals with closed circulatory systems and suggests an adaptive response. ${ }^{[18]}$ As such, not all anaemias are equal, and an understanding of the aetiology and physiological impact of anaemia is fundamental in determining transfusion thresholds for individual patients. Likewise, the decision to transfuse platelets based solely on a number may fail to consider the presence of platelet dysfunction (either congenital or acquired), concomitant coagulopathy, and the potential consequence of bleeding, should it occur.

\section{Conclusions}

The transfusion of blood products is one of the most routine interventions in healthcare. As the provision of blood products relies on a limited resource, transfusion practices need to be carefully scrutinised. A one-size-fits-all approach in clinical practice has appropriately fallen by the wayside, and, as this review demonstrates, the decision to transfuse blood products is no exception. While the referenced transfusion thresholds serve as a general guide that reflects the best available data, each patient, their comorbidities, preferences, as well as the clinical settings, should be considered prior to the prescription of a blood product transfusion.

\section{Declaration. None.}

Acknowledgements. None.

Author contributions. CEM drafted the manuscript; and RZ, AP, MS provided critical revision as content experts. All authors approved the final manuscript.

Funding. RZ receives an operating salary and operating funding from the Canadian Institutes of Health Research (CIHR) and the Lyonel G Israels Professorship in Hematology at the Max Rady College of Medicine, Winnipeg, Canada.

Conflicts of interest. None. 
1. South African National Blood Service. SANBS. 2016. https://sanbs.org.za (accessed 30 July 2019). 2. Narayan S, ed., Poles D, et al. on behalf of the Serious Hazards of Transfusion (SHOT) Steering Group. The 2018 Annual Report. 2019. https://www.shotuk.org/wp-content/uploads/myimages/SHOTReport-2018_Web_Version.pdf (accessed 30 July 2019).

3. Hebert PC, Wells G, Blajchman MA, et al. Transfusion requirements in critical care (TRICC): A multicentre, randomized, controlled clinical study. N Engl J Med 1999;340(6):409-417. https://doi. org/10.1056/NEJM199902113400601

4. Carson JL, Stanworth SJ, Roubinian N, et al. Transfusion thresholds and other strategies for guiding allogeneic red blood cell transfusion. Cochrane Database Syst Rev 2016;10:CD002042. https://dol. org/10.1002/14651858.CD002042.pub4

5. Carson JL, Guyatt G, Heddle NM, et al. Clinical practice guidelines from the AABB: Red blood cell transfusion thresholds and storage. JAMA 2016;316(19):2025-2035. https://doi.org/10.1001/ jama.2016.9185

6. Mazer CD, Whitlock RP, Fergusson DA, et al. Restrictive or liberal red-cell transfusion for cardiac surgery. N Engl J Med 2017;377(22):2133-2144. https://doi.org/10.1056/NEJMoa1711818

7. Retter A, Wyncoll D, Pearse R, et al. Guidelines on the management of anaemia and red cell transfusion in adult critically ill patients. Br J Haematol 2013;160(4):445-464. https://doi.org/10.1111/bjh.12143

8. Kumar A, Mhaskar R, Grossman BJ, et al. Platelet transfusion: A systematic review of the clinical evidence. Transfusion 2015;55(5):1116-1127. https://doi.org/10.1111/trf.12943

9. Estcourt LJ, Birchall J, Allard S, et al. Guidelines for the use of platelet transfusions. Br J Haematol 2017;176(3):365-394. https://doi.org/10.1111/bjh.14423

10. Kaufman RM, Djulbegovic B, Gernsheimer T, et al. Platelet transfusion: A clinical practice guideline from the AABB. Ann Intern Med 2015;162(3):205-213. https://doi.org/10.7326/M14-1589

11. Schiffer CA, Bohlke K, Anderson KC. Platelet transfusion for patients with cancer: American Society Schiffer CA, Bohlke K, Anderson KC. Platelet transfusion for patients with cancer: American Society
of Clinical Oncology clinical practice guideline update summary. J Oncol Pract 2018;14(2):129-133. of Clinical Oncology clinical practice g
https://doi.org/10.1200/JOP.2017.028902
12. Malouf R, Ashraf A, Hadjinicolaou AV, Doree C, Hopewell S, Estcourt LJ. Comparison of a therapeutic-only versus prophylactic platelet transfusion policy for people with congenital or therapeutic-only versus prophylactic platelet transfusion policy for people with congenital or
acquired bone marrow failure disorders. Cochrane Database Syst Rev 2018;5:CD012342. https://doi. acquired bone marrow failure disorders,

13. Sagmeister M, Oec L, Gmur J. A restrictive platelet transfusion policy allowing long-term support of outpatients with severe aplastic anemia. Blood 1999;93(9):3124-3126.

4. Estcourt LJ, Malouf R, Doree C, Trivella M, Hopewell S, Birchall J. Prophylactic platelet transfusion prior to surgery for people with a low platelet count. Cochrane Database Syst Rev 2018;9:CD012779. https://doi.org/10.1002/14651858.CD012779.pub2

15. Zarychanski R, Houston DS. Assessing thrombocytopenia in the intensive care unit: The past, present, and future. Am Soc Hematol Educ Program 2017;2017(1):660-666. https://doi.org/10.1182/ asheducation-2017.1.660

16. Slichter SJ, Kaufman RM, Assmann SF, et al. Dose of prophylactic platelet transfusions and prevention of hemorrhage. N Engl J Med 2010;362(7):600-613. https://doi.org/10.1056/NEJMoa0904084

17. Callum JL, Pinkerton PH, Lima A, Lin Y. Blood Easy 4: Blood Transfusions, Blood Alternatives Callum L, Pinkerton PH, Lima A, Lin Y. Blood Easy 4: Blood Transfusions, Blood Alternatives Zarychanski R, Houston DS. Anemia of chronic disease: A harmful disorder or an adaptive, Zarychanski R, Houston DS. Anemia of chronic disease: A harmful disorder or an adaptive,
beneficial response? Canad Med Ass J 2008;179(4):333-337. https://doi.org/10.1503/cmaj.071131

19. Stanworth SJ, Estcourt LJ, Powter G, et al. A no-prophylaxis platelet-transfusion strategy for hematologic cancers. N Engl J Med 2013;368(19):1771-1780. https://doi.org/10.1056/NEJMoa1212772

Accepted 29 July 2019 